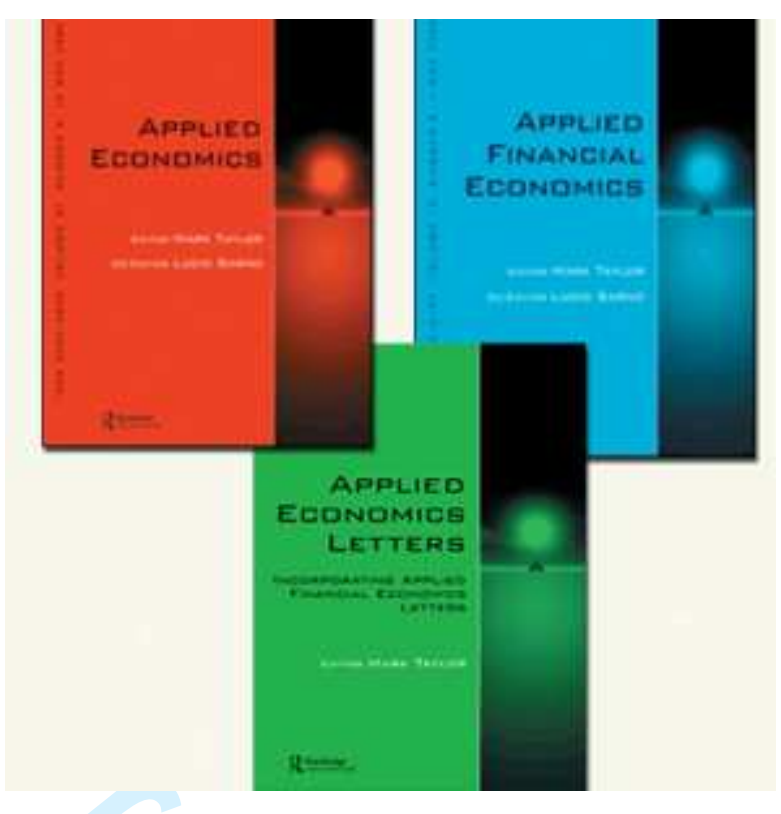

\title{
GOVERNMENT SOCIAL SPENDING AND GDP: HAS THERE BEEN A CHANGE IN SOCIAL POLICY?
}

\begin{tabular}{|c|c|}
\hline Journal: & Applied Economics \\
\hline Manuscript ID: & APE-2009-0409.R1 \\
\hline Journal Selection: & Applied Economics \\
\hline $\begin{array}{r}\text { Date Submitted by the } \\
\text { Author: }\end{array}$ & 16-Jul-2010 \\
\hline Complete List of Authors: & $\begin{array}{l}\text { Clemente, Jesus; Zaragoza University, Analisis Economico } \\
\text { Marcuello, Carmen; Zaragoza University, Organización de Empresas } \\
\text { Montañes, Antonio; Zaragoza University, Analisis Economico }\end{array}$ \\
\hline JEL Code: & $\begin{array}{l}\text { H53 - Government Expenditures and Welfare Programs }<\text { H5 - } \\
\text { National Government Expenditures and Related Policies }<\text { H - Public } \\
\text { Economics, O57 - Comparative Studies of Countries }<\text { O5 - } \\
\text { Economywide Country Studies }<\mathrm{O} \text { - Economic Development, } \\
\text { Technological Change, and Growth, I38 - Government } \\
\text { Policy|Provision and Effects of Welfare Programs }<\text { I3 - Welfare and } \\
\text { Poverty < I - Health, Education, and Welfare }\end{array}$ \\
\hline Keywords: & $\begin{array}{l}\text { Government Social Spending, GDP, Changes in social policy, } \\
\text { Cointegration }\end{array}$ \\
\hline
\end{tabular}




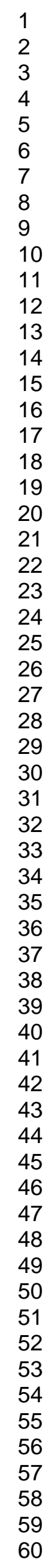

5.) ShholaroNE" $_{\text {Manuscript Central }}$ . 10

25

26

27

29

30

32

33

34

35

36

37

38

41

42

43

45

46

47

48

49

51

52

53

54

55

57

58

59

60 


\title{
GOVERNMENT SOCIAL SPENDING AND GDP: HAS THERE BEEN A CHANGE IN SOCIAL POLICY?
}

\begin{abstract}
Government Social Spending is made up of a very heterogeneous range of variables, monetary transfers for retirement or illness, unemployment benefits, family services, active labour market policies and health expenditure. We believe that each of these components is of enormous importance to the economic development of a country. As has often been affirmed, however, Government Social Spending is one of the economic aggregates most sensitive to the ups and downs of economic growth. In moments of crisis, sharp cuts are almost immediate, and these may or may not be recovered when times are good. In this paper, we examine the sensitivity of Government Social Spending to the evolution of GDP in order to reveal the relationship between the two.
\end{abstract}

Keywords: Government Social Spending, GDP, changes in social policy. 


\section{GOVERNMENT SOCIAL SPENDING AND GDP: HAS THERE BEEN A CHANGE IN SOCIAL POLICY?}

\section{Introduction}

In the European context, it has often been argued that Government Social Spending (GSS) is very high and should be constrained or reduced. For example, countries such as France and Germany are under pressure from both the European Union and their own economic situation to reduce GSS. The indebtedness of these countries threatens compliance with EU monetary stability requirements, while both the effectiveness and the sustainability of the welfare state have been questioned. As a result, both countries have been obliged to address possible reductions in GSS in order to maintain the stability pact, resulting in the announcement of cuts in pension systems and, in general, in different components of GSS. This situation is not new, since many other developed nations running a welfare state have already found themselves engaged in similar processes and it may, therefore, be of interest to examine the response of the different governments in a crisis context.

The current situation is indeed very similar to that of any country finding itself in a moment of crisis in the relatively recent past, where the resort to economic measures based on the constraint of the public deficit by lowering GSS has been a common policy. In fact, social expenditure is usually the prime target of proposals to solve the problems associated with fiscal imbalances, despite its recognised importance for the welfare of different groups among the population.

The issue is important from various points of view. Firstly, it may provide evidence for or against the theories on which policies have been based. For example, Kittel and Obinger (2003) examine these theories (race to the bottom, old politics, the new logic of politics, match-up and the new politics approach) in the light of the various elements that define social policy and which embrace issues such as convergence, economic growth and the behaviour of political parties in times of crisis. The authors find no conclusive evidence in favour of any of these theories. Secondly, as both Kittel and Obinger (2003) and Fic and Ghate (2005) argue, the golden age of the welfare state in the western economies appears to have reached its end some time around 1990. Unquestionably, the crisis of the 1990s ushered in sharp cuts in GSS that have not been 
reversed in the following period of expansion. A rigorous statistical analysis is necessary to obtain results allowing comparison with the situation underlying the current debate. Thirdly, it is important to analyse the relationship between GSS and national income or production (Herce et al. 2000, Herce et al. 2001, Herce et al. 2003, Auteri and Costantini, 2004, Wahab, 2004, Bellettini and Berti, 2000, Fic and Ghate, 2005). The effects of GSS on growth, and the analysis of causality, provide significant insights into the outcomes of different policy approaches (Arjona et al., 2002 is an excellent review of empirical work in this area). Herce et al. (2001) examine the issue of causality in depth, finding evidence to support a demand-based theory which states that it is the evolution of incomes that drives the behaviour of social expenditure. Thus, income elasticity is found to be one of the key factors for the analysis of the behaviour of this expenditure in a context where elasticity may actually have changed due to policy shifts in the countries concerned.

In this light, it is important to consider the evolution of GSS and, in particular, the part excluding health spending which, unlike GSS, has already been sufficiently studied in its own right. We propose to undertake this analysis using an approach that includes recent contributions in the context of cointegration. This topic has been considered in Auteri and Constantini (2004) where the relationship between Government Social Spending and GDP is estimated without changing parameters. This restriction does not seem to hold in practice and the transmission of the changes in GDP may vary across the time. In this way, it seems sensible to use methods that allow us to detect changes in the relationship between GDP and Government Social Spending, which could be interpreted as changes in the Social policies of these countries.

A demand-based approach will allow us to analyse how GSS responds at different income levels. An additional question that can be studied is whether GSS is a luxury or a necessity good. The welfare state has grown considerably in western countries and the associated services could be close to saturation in some countries, in which case the sensitivity of this type of expenditure to variations in income will probably have declined significantly with economic growth. This means that GSS could be considered a luxury good in lower-income nations. As the need is covered and gradually comes to be taken for granted, however, perceptions may change, and it may come to be seen as a necessity good. 
The rest of the paper is organised as follows. Section 2 describes the data used in the paper. Section 3 presents the econometric methodology employed, based on the use of panel data unit root/cointegration tests. Section 4 reports the results obtained. The paper finishes with a review of the most important conclusions.

\section{Government Social Spending: a descriptive analysis.}

From a political, social and economic point of view, we may identify four basic welfare state models in OCDE economies. Scheepers et al. (2002) and Buhigas-Schubert and Martens (2005) define the following models: (1) the Nordic welfare state model represented by Sweden, Norway, Iceland, Denmark and Finland, in which we find a universal benefits system; (2) the Anglo-Saxon model, which includes the United States, the United Kingdom, Canada, Ireland and Australia and is based on a selective welfare state; (3) the Continental/Conservative model representing the more interventionist system applied in Germany, Austria, France, Belgium and the Netherlands; and (4) the Southern European model comprising Spain, Greece, Italy and Portugal, which is sometimes included in the Continental model, although it presents different common characteristics. Finally, there is the Japanese social policy model, which differs from the others and includes greater involvement on the part of business ${ }^{1}$.

This paper focuses on GSS excluding health expenditure. There are three reasons for this. First, health spending has already been exhaustively analysed in numerous papers. Secondly, health expenditure is associated with processes for the accumulation of human capital (Strulik, 2004, Rivera and Currais, 2004), while social spending policies are implemented in tandem with the accumulation of social capital (Rothstein and Stolle, 2002; Kumlin and Rothstein, 2005). Consequently, the sensitivity of these two expenditures to changes in income may differ from the standpoint of both individual decisions (private spending) and government policy. Finally, we may mention the recent debate concerning the sustainability of the welfare state in the western economies, both from the financial point of view and in terms of the incentives provided to economic agents in a given society.

As a starting point, we may note the variability in the intensity of spending in different countries represented as the percentage of GDP applied to social policy. Figure 1 shows

\footnotetext{
${ }^{1}$ Nevertheless, the term social spending or social policy covers a wide range of country-specific forms and decisions and the particular circumstances of the beneficiary groups. Consequently, any analysis of the components of social spending must take into account the possibility of significant differences, and comparisons can only be made with caution (Adema, 2001).
} 
this percentage for different countries in three years, 1981, 1991 and $2001 .^{2}$ We should first note the heterogeneity of the percentages reflected. The percentages for the nonEuropean and Southern European nations are significantly lower, in particular when compared to the Nordic countries. This corroborates the existence of different social protection systems as defined in Scheepers et al. (2002).

Figure 1: Government Social Spending without health as percentage of GDP

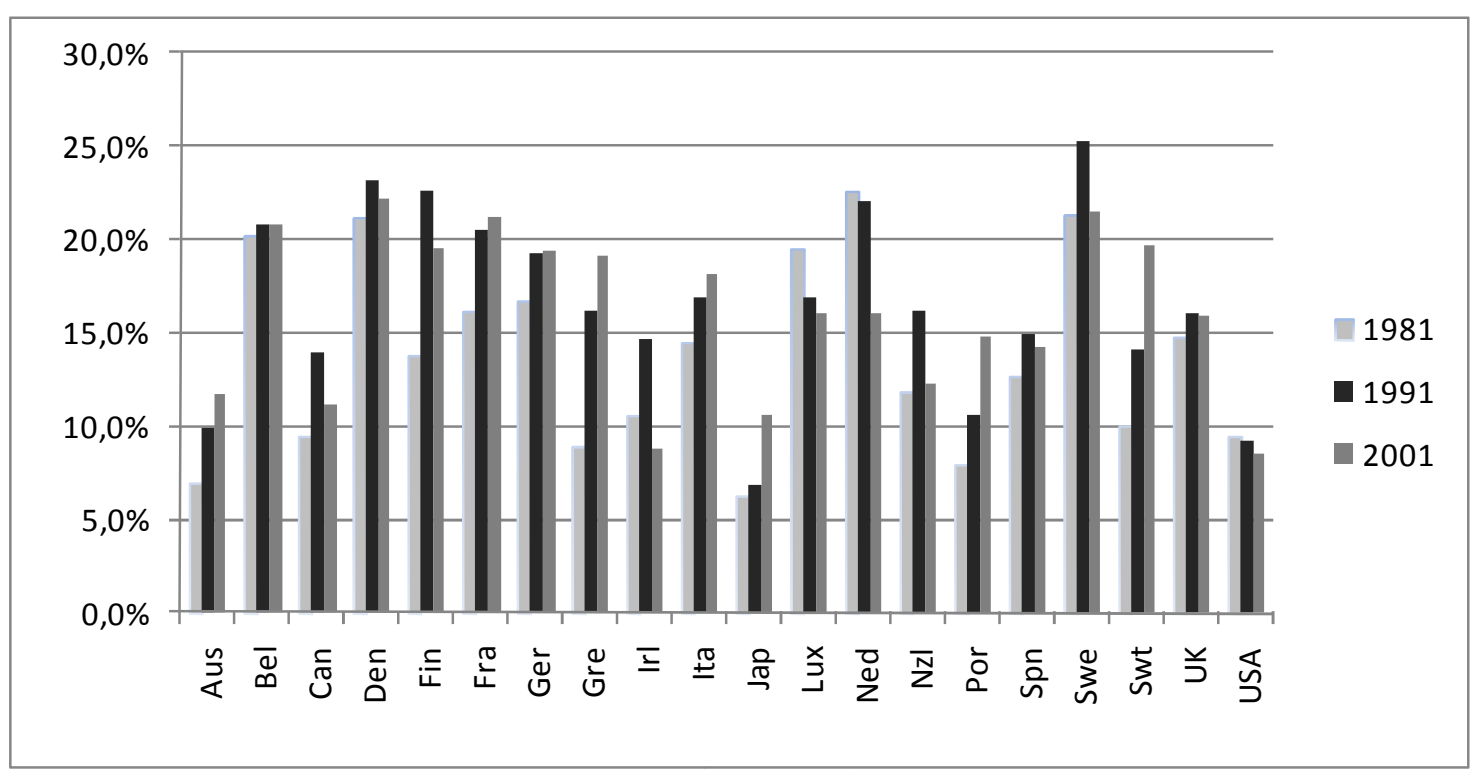

Source: 2004 OECD Data Base

Furthermore, this figure reveals the presence of a peak around 1990, which is followed by two different behaviours: the ratio stabilises for the countries with high levels of social protection and clearly drops for the rest.

The behaviour of countries with lower levels of protection differs substantially. While certain stability is visible in the non-European countries, the nations of Southern Europe follow two distinct patterns. The profile in Spain is similar to that of the rest of Europe but, in Italy, Portugal and Greece, GSS continued to rise.

In short, the pattern is mixed but, in general terms, the 1990s saw a contraction in Government Social Spending, excluding Government Health Expenditure, measured as a percentage of GDP, except in certain Southern European countries with already low levels of social protection and in Germany.

\footnotetext{
${ }^{2}$ The data base employed is described in next section.
} 
In this context, it may be of interest to consider the dynamic evolution of this percentage. Figures 2 and 3 present the data for a set of countries in order to illustrate the differentiated pattern described above. The profile of Sweden begins with slow growth followed by a decrease while the German pattern is stable in the early years but subsequently takes an upward path and the US and UK patterns do not appear to change.

Similar conclusions can be drawn if Figure 3 is analysed. We can observe that the Netherlands ratio has a downward trend whilst this ratio shows an upward trend for Portugal, Japan and Italy.

These figures illustrate the heterogeneity of the behaviour of the GSS/GDP ratio, both from the standpoint of the dynamic pattern over time and taking into account the size of the welfare state, clearly reflecting the importance of the local peculiarities of the countries included in the sample.

Figure 2: Evolution of Government Social Spending without health as percentage of GDP

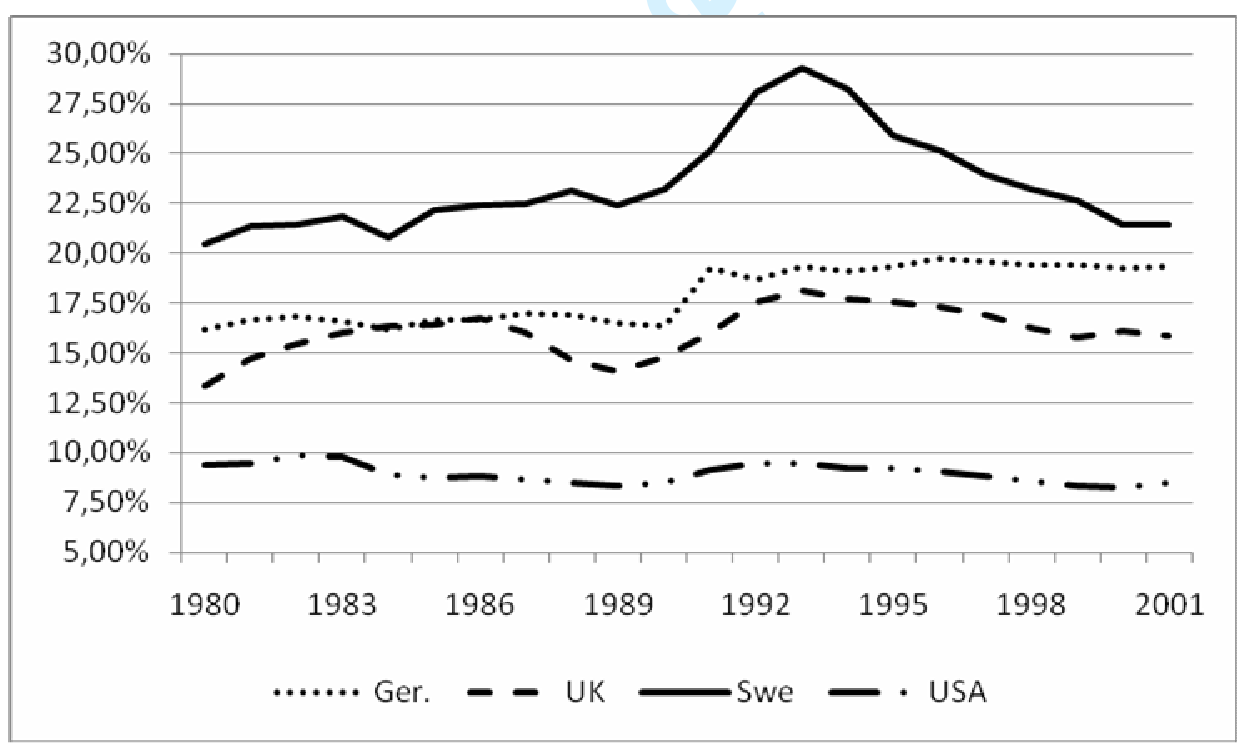

Source: 2004 OECD Data Base

Figure 3: Evolution of Government Social Spending without health as percentage of GDP 


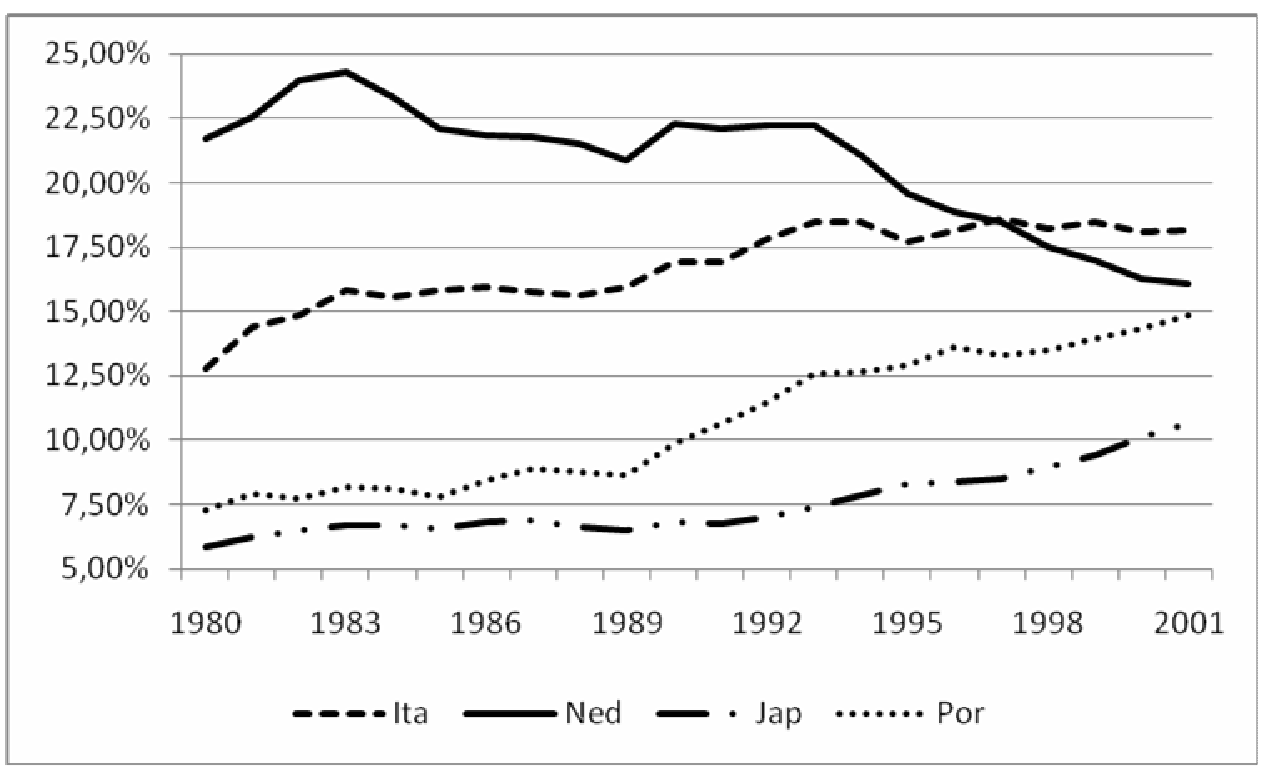

Source: 2004 OECD Data Base

Figure 4: Evolution of Standard Deviation of Government Social Spending without health as percentage of GDP

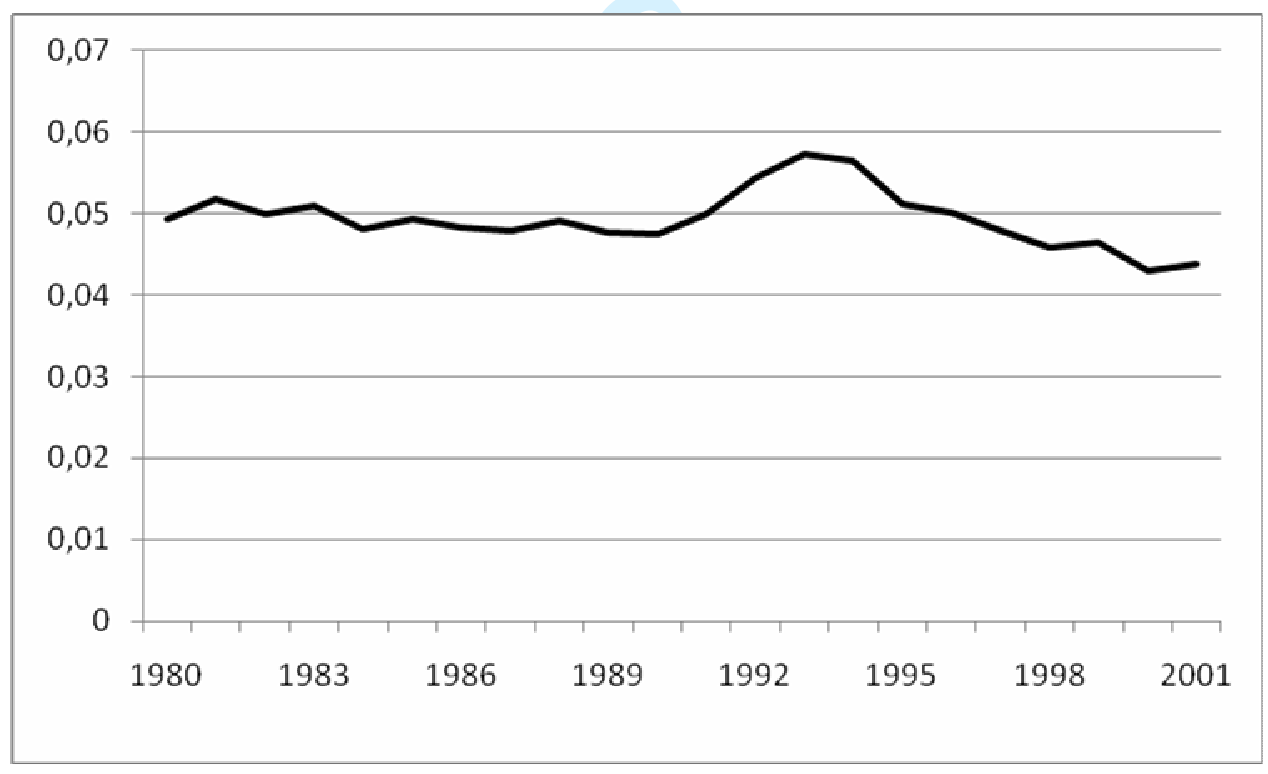

Source: 2004 OECD Data Base

Finally, we can also analyse the possible existence of some degree of convergence in the GSS/GDP ratio. To that end, Figure 4 reports the so-called sigma convergence, which provides some measure of the dynamic evolution of the standard deviation of the GSS/GDP ratio. We can conclude that, after the 1991 crisis, the standard deviation diminished, which could provide some evidence in favour of the existence of a type of convergence process, confirming the results previously obtained in Alonso et al. (1998), Alesina et al. (2005) and in Attia and Berenguer (2007). These papers highlight the 
importance of the EU regulation, directives and decisions as element that could have been favouring this process.

\section{Data and methodology}

\subsection{The data.}

The data employed in this paper has been obtained from the 2001 OECD Data Base, commonly used in research of this nature, which includes values for the period from 1980 through 2001. The countries included in the sample are Australia, Belgium, Canada, Denmark, Finland, France, Germany, Greece, Ireland, Italy, Japan, the Netherlands, New Zealand, Portugal, Spain, Sweden, the United Kingdom and the United States. It would be possible to use a larger sample if only a part of social expenditure, namely, transfer spending were considered as in Fic and Ghate (2005). However, our standpoint is associated with total GSS because expenditure on employment and other active social policies is very significant in some nations. Consequently, while Fic and Ghate (2005) opted to expand the sample size despite the loss of some of the GSS information, we have chosen the alternative of a smaller sample that includes the whole of GSS. Evidently both positions are open to criticism and represent alternative, yet complementary, points of view.

\subsection{Time series properties of the series: Unit root tests}

This subsection analyses the time series properties of our data set. It is well known that the presence of unit roots determines the most appropriate econometric methodology to be used. Thus, we should first test for the unit root null hypothesis in our series in order to determine the integration order of the variables. To that end, we could have followed a single approach and applied the Dickey-Fuller family of tests. However, given the characteristics of our sample, with only information for the last 20 years, we have chosen to focus the analysis on panel data unit root statistics. This approach has the advantage of providing better statistics properties than the standard unit root statistics (more powerful and no significant size distortions). Furthermore, it seems appropriate to use the second generation panel data unit root tests because of the possible presence of cross-correlation. The emergent literature related to this issue is large and includes the papers of Im et al. (2003), Levin et al. (2002) and Maddala and Wu (1999), amongst 
many others ${ }^{3}$. In this paper, we will follow Pesaran (2007) given that the Monte Carlo simulations reported in that paper show that these tests offer better statistical properties. The statistics recommended in Pesaran (2007) are based on the cross-sectionally augmented version of model (1):

$$
\Delta y_{i t}=a_{i}+\alpha_{i} y_{i t-1}+c_{i} \bar{y}_{t-1}+\sum_{j=0}^{p} d_{i j} \Delta \bar{y}_{t-j}+\sum_{i=1}^{p} \delta_{i j} \Delta y_{i t-1}+u_{i t}
$$

where $\bar{y}_{t}$ means the cross-sectional mean of $y_{i t}$. If $t_{i}(N, T)$ is the t-ratio for testing the null hypothesis $H_{0}: \alpha_{i}=0$ in (4), then the generalization of the Im et al (2003) statistic defined in Pesaran (2007) can be represented as:

$$
\mathrm{CIPS}=\mathrm{N}^{-1} \sum_{i=1}^{N} t_{i}(N, T)
$$

which can be understood as an extension of the IPS statistic. Alternatively, we can also use a truncated version of this CIPS statistic defined as follows:

$$
\operatorname{CIPS}^{*}=\mathrm{N}^{-1} \sum_{i=1}^{N} t_{i l}^{*}(N, T)
$$

where $t_{i}{ }^{*}(N, T)$ is a truncated version of the statistic $t_{i}(N ; T)$, from which the values that are too small and too large are removed in such a way that the values of the $\mathrm{t}^{*}(\mathrm{~N} ; \mathrm{T})$ test belongs to the interval $(-\mathrm{k} 1, \mathrm{k} 2)$. The values of $\mathrm{k} 1$ and $\mathrm{k} 2$ depend on the deterministic elements included in (4) and are reported in Table 2 of Pesaran (2007).

The results that we have obtained are reported in Table 1 . We can observe that the unit root null hypothesis cannot be rejected, whilst the presence of a second unit root is rejected, except when two lags are considered in order to remove the possible autocorrelation pattern. However, we should note that the use of the second lag is not supported for the data if the AIC or the MIC criterion are employed and, furthermore, the second unit root would not have a clear economic interpretation. Thus, the unit root analysis leads us to the draw the conclusion that both GDP and the Non-Health Social Expenditure exhibit a unit root and, consequently, the cointegration analysis is the most adequate to study the relationship.

\subsection{Estimation of long term relationships: Panel data cointegration analysis.}

\footnotetext{
${ }^{3}$ We should also highlight the papers of Breitung and Das (2005), Bai and Ng (2004), Moon and Perron (2004) or Phillips and Sul (2003).
} 
Having offered evidence in favour of the I(1) hypothesis, the existence of a long-run structural relationship between the Non-Health Social Expenditure and the GDP of a particular country is the next question. The initial model specification can be stated as follows:

$$
\log \mathrm{S} E_{\mathrm{t}}^{\mathrm{i}}=\beta_{1 i}+\beta_{2 i} \log \mathrm{PIB}_{\mathrm{t}}^{\mathrm{i}}+\mathrm{u}_{\mathrm{it}}
$$

where the endogenous variable is the logarithm of Non-Health Social Expenditure of country $i$ in the period $t$, whilst the GDP of the $i$-th country in period $t$ is the explanatory variable.

We test the non-cointegration null hypothesis by analysing the presence of a unit root in the perturbation of (7). Again, we have adopted a panel data perspective. There is a relatively wide range of statistics available, although our preferences are the group test defined in Pedroni (1999, 2004), which can be considered the panel data extension of the Engle-Granger statistics. Following this author, the statistics that we have used can be defined as:

$$
P D=\frac{N^{-1 / 2} \tilde{Z}_{t_{N, T}}-\Theta \sqrt{N}}{\sqrt{\Psi}} \Rightarrow N(0,1)
$$

where $\widetilde{Z}_{t_{N . T}}$ is the mean group t-type statistic for testing the null hypothesis that the perturbation of the i-th model exhibits a unit root. We should recall that we can follow a parametric or a non-parametric approach in order to take into account the possible existence of autocorrelation in these perturbations. In the first case, we should calculate the statistics of the Dickey-Fuller family, whilst the Phillips-Perron statistics are obtained in the second. The values of the parameters $\Theta$ and $\Psi$ that controls the convergence of the statistics towards a Normal distribution depends on the number of explanatory variables included in the model specification. Pedroni (2004) reports the asymptotic approximations.

However, the earlier specification may not to be enough to capture the relationship between Non-Health Social Expenditure and GDP if some changes in the parameters (structural breaks) appear. For example, Clemente et al. (2004) offers evidence in favour of the structural break hypothesis when the relationship between total Health Expenditure and GDP of a group of the OECD countries is analysed. Thus, it seems sensible to admit the possible existence of a break in model (7). To incorporate the 
break, we add some dummy variables to the previous specification in order to capture these changes. The new model specifications can be stated as follows:

$$
\log \mathrm{GH}_{\mathrm{t}}^{\mathrm{i}}=\alpha_{1 i}+\alpha_{2 i} \log \mathrm{PIB}_{\mathrm{t}}^{\mathrm{i}}+\alpha_{3 i} \mathrm{D}_{\mathrm{t}}^{\mathrm{i}}+\mathrm{u}_{\mathrm{it}}
$$

when only a change in the intercept is considered or, more generally,

$$
\log \mathrm{GH}_{\mathrm{t}}^{\mathrm{i}}=\alpha_{1 i}+\alpha_{2 i} \log \mathrm{PIB}_{\mathrm{t}}^{\mathrm{i}}+\alpha_{3 i} \mathrm{D}_{\mathrm{t}}^{\mathrm{i}}+\alpha_{4 i}\left(\mathrm{D}_{\mathrm{t}}^{\mathrm{i}} \log \mathrm{PIB}_{\mathrm{t}}^{\mathrm{i}}\right)+\mathrm{u}_{\mathrm{it}}
$$

when both the intercept and the slope changes. In the previous equations, $D_{t}{ }^{i}$ means a dummy variable that takes the value 1 for the variable I when $\mathrm{t}>\mathrm{TB}^{\mathrm{i}}$, with $\mathrm{TB}^{\mathrm{i}}$ being the period when the break changes.

In a recent paper, Banerjee and Carrión (2006) have defined a new family of panel data cointegration statistics that test for the non-cointegration null hypothesis when the specification model includes the presence of a structural change, as is the case of models (9) and (10). Their proposal is based on an extension of the statistics for single series designed in Gregory and Hansen (1996) to the case of panel data. Banerjee and Carrión (2005) again propose a number of different statistics, following the papers of Pedroni (1999, 2004). However, we will only use those statistics that are based on mean group t-statistics, which can be defined in a similar way to that reported in (8), although the asymptotic values of the parameters $\Theta$ and $\Psi$ change and are reported in Table 4 of Banerjee and Carrión (2006).

Finally, we should note that we have considered the two above mentioned families of ttests (Dickey-Fuller and Phillips-Perron) and that, in order to take into account the cross-sectional dependency, we have also obtained these statistics for the variables measured in differences with respect to the cross-sectional mean. The results that we have obtained are reported in Table 2.

The first column of Table 2 reports the value of the EG statistic for each model, as well as the mean group t-ratio (for the raw data and for the cross-sectional mean corrected data). The analysis of these group t-ratios cannot lead us to reject the non-cointegration null hypothesis for the system. Thus, if we finished the study at this point, we should conclude that there is no evidence in favour of a long-run relationship between NonHealth Social Expenditure and GDP. 


\section{International analysis of the relationship between Government Social Spending and GDP}

The analysis of the results obtained from the application of the econometric techniques described in the previous section begins with Table 2, where the estimation of the parameters of the models employed to capture the relationship between Non-Health Social Expenditure and GDP for our group of countries is reported. We should recall that we are considering three different specifications, represented by models (4), (6) and (7). In order to select the most appropriate model for each country, we have considered the t-ratios associated with the dummy variables, these t-ratios having been obtained from the use of Fully-Modified estimation. Finally, we have divided the countries into four different blocks, as indicated in Section 2 above, depending on the welfare system in place (Nordic, Anglo-Saxon, Continental and Latin, without considering Japan) in order to make the analysis of the results easier.

First, all the countries admit the presence of a change in their particular cointegration relationship. The period when this break occurs is closely related to the beginning of 1990s, except for the cases of New Zealand and Ireland whose estimations of the break time is slightly earlier. This change has been documented in other papers referring to the public sector in general, such as Hansen and Stuart (2003), and it has also been associated with the crisis of the early 1990s and the argument that the public sector had become too large. In any event, we should consider whether the slimming down of the public sector has been achieved by cuts in the welfare state.

Table 2 also shows that the change has implied a significant reduction in the elasticity of Non-Health Social Expenditure to GDP in the Latin nations. Hence, we may affirm 
that there has been a reform of the welfare state, confirming our initial hypothesis that the current situation is not new, but has already occurred in earlier periods.

Another regularity that may be observed is that the countries exhibiting a decline in elasticity are generally those with higher elasticity prior to 1992. This evidence confirms a convergent trend in social policy at the level of the countries analysed. Furthermore, the change is so pronounced for the Netherlands that the elasticity estimated for the second half of the 1990s is actually negative, although we cannot reject that the final elasticity is different from 0 . Thus, we can only affirm that this country exhibits a significant reduction in the response of Non-Health Social Expenditure.

With regard to the estimated values prior to 1990 , an elasticity $\left(\beta_{3}\right)$ of less than one was found in seven countries (Denmark, Sweden, Ireland, the USA, Belgium, Luxembourg and the Netherlands), which confirms the hypothesis that Non-Health Social Expenditure was considered a luxury good. This situation changes completely after 1990. In this decade, 13 countries exhibit an elasticity of less than one while in Portugal elasticity declines sharply and Japan is the only country where elasticity grows. Hence, we may affirm, in general terms, that Non-Health Social Expenditure is becoming a necessity good.

To sum up, the data provide evidence to support the existence of a change in the social policy implemented by the countries included in the sample. This change reveals a trend towards a cut-back in the welfare state in terms of a reduction in the sensitivity of expenditure of this kind to the evolution of national incomes, a phenomenon that could be associated with the perception that the services provided by the State have reached saturation.

\section{Conclusions}

The evolution of Government Social Spending indicates that periods of crisis have ushered in policies aimed at constraining and even cutting expenditure in order to alleviate the public deficit. Furthermore, examination of Government Social Spending as a percentage of GDP in the OECD countries during the period 1980-2001 reveals a very mixed pattern. In this paper, we have analysed the evolution of Government Social Spending from a demand-based perspective. We have considered how income affects the amount of public funds earmarked for Government Social Spending. The 
methodology employed is based on cointegration analysis, allowing evaluation of changes in the parameters of the models estimated and the detection of changes in the behaviour of the variable. By using a double logarithmic estimation, we were able to calculate the income elasticity of Government Social Spending and ask whether GSS is a luxury or a necessity good.

The countries included in the sample were Australia, Belgium, Canada, Denmark, Finland, France, Germany, Greece, Ireland, Italy, Japan, the Netherlands, New Zealand, Portugal, Spain, Sweden, the United Kingdom and the United States, and the analysis focused on Government Social Spending excluding Government Healthcare Expenditure. This was because Government Healthcare Expenditure has already been the subject of numerous studies in the academic literature, and the approach allowed us to focus on the part of Government Social Spending that has received the least attention. The countries analysed were placed in five groups defined on the basis of the welfare models proposed by Scheepers et al. (2002) and Buhigas-Schubert and Martens (2005). In this way, we distinguished between countries applying the Nordic, Continental/Conservative, Anglo-Saxon and Southern European models, as well as Japan. Based on a descriptive analysis, the first point of note was the existence of considerable variation in the intensity of Government Social Spending in the different countries measured in terms of the share of GDP allocated. Additionally, the early 1990s showed a general round of spending cuts (again measured as a percentage of GDP) with the exception of certain Southern European nations and Germany.

Based on our estimations, five of the 18 countries analysed (Denmark, New Zealand, Ireland, France and Japan) did not exhibit any cointegration relationship between GSS and GDP. For the rest of the countries, GSS and GDP were found to be cointegrated, although this relationship changes at the beginning of the 1990s. This is a very important result because it indicates a modification in social policy in some economies where we can observe a clear trend towards a reduction in the share of GDP represented by Government Social Spending. Furthermore, if we also take into account the values of the estimated elasticities, we may affirm that Government Social Spending was considered a luxury good prior to the 1990s. From 1990 onwards, however, it came to be seen as a necessity good though it continued to behave as a luxury good in a few countries. 
To sum up, the results reported in the paper provide useful information about the existence of a significant change in the social policy of various developed nations in the early 1990s. This issue should be a matter of concern for the citizens of countries with low levels of social protection, because the likely cuts will mean a lower level of social services provision. For example, the reduction in the income elasticity of the Southern European nations represents a backward step in the process of convergence towards the system of social provision enjoyed by other countries. In these countries, the situation appears brighter, because the social protection system covers practically all needs and if the current situation is maintained, services are unlikely to be reduced.

Let us end by pointing out some extensions of the current analysis which could provide additional insights to those reported in this paper. First, it would be worth considering the role of the private sector in the provision of services in countries with low levels of social protection and to compare private delivery with the corresponding public sector spending in countries with higher levels of protection. Secondly, it would be interesting to carry out a detailed investigation of the links between Government Social Spending and social capital as a driver of economic growth, which would mean examining the social policy mechanisms associated with this triple relationship. Finally, the present analysis should be repeated with the inclusion of the most recent data given that it is of great interest to analyse whether the 2008 international crisis has implied a significant reduction in the levels of social protection due to the need of the most important economies to reduce their public deficits.

\section{References.}

Adema, W. (2001) Net Social Expenditure, Labour Market and Social Policy Occasional Paper, No.52, 2nd Edition, OECD.

Alesina, A., Angeloni, I. and Schuknecht, L. (2005) What Does the European Union? Public Choice, 123, 275-319.

Alonso, J., Galindo, M. and Sosvilla-Rivero, S. (1998). Convergence in Social Protection Benefit Across EU Countries. Applied Economics Letters. 5: 153-155.

Arjona, R., Ladaique, M. and Pearson, M. (2002). Social Protection and Growth, OECD Economic Studies. 35: 8-58.

Attia, N. and Berenguer, V. (2007). Social Protection in the European Union: Impact of the Maastricht Treaty. Panoeconomicus. 4: 469-487. 
Auteri, M. and Costantini, M. (2004). Is social Protection a Necessity or a Luxury Good? New Multivariate Cointegration Panel Data Results, Applied Economics. 36: 1887-1898.

Bai, J. and S. Ng, (2004): “A PANIC Attack on Unit Roots and Cointegration”, Econometrica, 72, 1127-1177.

Banerjee, A. and Carrión, J.L. (2006). Cointegration in Panel Data with Breaks and Cross-Section Dependence, European Central Bank, Working Paper 591.

Bellettini, G. and Berti Ceroni, C. (2000). Social Security Expenditure and Economic Growth: and Empirical Assessment, Research in Economics. 54: 249-275.

Buhigas-Schubert, C. and Martens, H. (2005). The Nordic model: A recipe for European success?, European Policy Center, Working Paper No.20.

Breitung, J. and Das, S., (2005): "Panel Unit Root Tests Under Cross Sectional Dependence", Statistica Neerlandica, 59, 414-433.

Clemente, J., Marcuello, C., Montañes, A., and Pueyo, F. (2004). On the international stability of health care expenditure functions: are government and private functions similar, Journal of Health Economics. 23: 589-613.

Dickey D, Fuller W (1979). Distribution of the Estimators for Autoregressive Time Series With a Unit Root, Journal of the American Statistical Association. 74: 427431.

Engle, R. and W. Granger (1987). Co-integration and Error Correction: Representation, Estimation and Testing, Econometrica. 55: 251-276

Fic, T. and Ghate, C. (2005). The Welfare State, Thresholds, and Economic Growth, Economic Modelling. 22: 571-598.

Gregory, A.W., and Hansen, B.E., (1996). Residual-Based Tests for Cointegration in Models with Regime Shifts, Journal of Econometrics. 70: 99-126.

Hansen, A. and C. Stuart (2003). Peaking of Fiscal Sizes of Government, European Journal of Political Economy. 19. 669-684.

Herce, J., Sosvilla-Rivero, S. and Lucio, J. (2000). Social Protection Benefits and Growth: Evidence from the European Union, Applied Economics Letters. 7: 255-258. 
Herce, J., Sosvilla-Rivero, S. and Lucio, J. (2001). Growth and Welfare State in the EU: A Causality Analysis, Public Choice. 109: 55-68.

Herce, J., Sosvilla-Rivero, S. and Lucio, J. (2003). Convergence in Social Protection Across EU Countries, 1970-1999: A Causality Analysis, Public Finance. 53: 269281.

Im K., Pesaran M., Shin Y. (2003). Testing for Unit Roots in Heterogeneous Panels, Journal of Econometric. 115: 53-74.

Kittel, B. and H. Obinger (2003). Political Parties, Institutions, and the Dynamics of Social Expenditure in Times of Austerity, Journal of European Public Policy. 10(1): $20-45$.

Kumlin, S. and Rothstein, B. (2005). Making and Breaking Social Capital: The Impact of Welfare State Institution. Comparative Political Studies. 38: 339-365.

Levin A, Lin F, Chu C. (2002): "Unit root tests in panel data: asymptotic and finitesample properties" Journal of Econometrics, 108, 1-24.

Maddala GS, Wu S. (1999): “A comparative study of unit root tests with panel data and a new simple test” Oxford Bulletin of Economics and Statistics, 61, 631-652.

Moon, H.R., and B. Perron, (2004): “Testing for a Unit Root in Panels with Dynamic Factors", Journal of Econometrics, 122, 81-126.

Ng, S., Perron, P., (1995). Unit Root Test-ARIMA Models with Data-Depending Method for Selection of the Truncation Lag, Journal of the American Statistical Association. 90: 268-281.

Ng, S. and P. Perron, (2001). Lag Length Selection and the Construction of Unit Root Tests with Good Size and Power. Econometric. 69: 1519-1554.

Pedroni, P. (1999). Critical Values for Cointegration Tests in Heterogeneous Panels with Multiple Regressors, Oxford Bulletin of Economics and Statistics: Special Issue: 653-670.

Pedroni, P. (2004). Panel Cointegration. Asymptotic and Finite Sample Properties of Pooled Time Series Tests with an Application to the PPP Hypothesis, Econometric Theory. 20: 597-625. 
Perron, P. (1989). The Great Crash, the Oil Price Shock, and the Unit Root Hypothesis, Econometrica. 57: 1361-1401.

Phillips PCB and Perron P (1988): “Testing for a Unit Root in Time Series Regression”, Biometrika, 75, 335-346.

Phillips, P.C.B. and D. Sul, (2003): "Dynamic Panel Estimation and Homogeneity Testing Under Cross Section Dependence”, Econometrics Journal, 6, 217-259.

Rivera, B. and L. Currais (2004). Public Health Expenditure and Porductivity in the Spanish Regions: A Dynamic Panel Data Model, World Development. 32(5): 871885 .

Rothstein, B. and Stolle, D. (2002). How Political Institutions Create and Destroy Social Capital: an Institutional Theory of Generalized Trust, Paper Prepared for the 98 Meeteing of the American Political Science Association in Boston, MA.

Sargan, J. D. and A. Bhargava (1983). Testing Residuals from Least Squares Regression for Being Generated by the Gaussian Random Walk, Econometrica. 51:153-174.

Sheepers, P., Grotenhueis, M. and Gelissen, J. (2002). Welfare States and Dimensions of Capital Social. Cross-Country Comparisons of Social Contacts in European Countries, European Societies. 42: 185-207.

Strulik, H. (2004). Economis Growth and Stagnation with endogenous health and Fertility, Journal of Population Economics. 17(3): 433-453.

Wahab, M. (2004). Economic Growth and Government Expenditure: Evidence from a New Test Specification, Applied Economics. 36: 2125-2135. 
Table 1. CIPS statistic.

Non-Health Government

PIB

Social Expenditure

lags

Panel A. Testing for the null Hypothesis I(1) vs I(0)

$\mathrm{p}=0$

$-1.94$

$-2.02$

$\mathrm{p}=1$

$-2.28$

$-2.16$

$\mathrm{p}=2$

$-1.90$

$-2.10$

Panel B, Testing for the null Hypothesis I(2) vs I(1)
$\mathrm{p}=0$
$-4.26^{a}$
$-2.73^{a}$
$\mathrm{p}=1$
$-3.36^{a}$
$-2.24^{b}$
$\mathrm{p}=2$
$-1.49$
$-1.81$

This table reports the CIPS statistic for testing the panel data unit root null hypothesis. We should note that the results of the CIPS* statistic coincide with those of the CIPS. The values of Panel A have been obtained including an intercept and a deterministic trend in the model specification, whilst those of Panel B have been obtained including only an intercept. Critical values are reported in Table 2 of Pesaran (2007).

${ }^{a}, b$ mean the rejection of the null hypothesis for a given $1 \%$ and $5 \%$ significance level, respectively. 
Table 2. Cointegration Analysis and Estimation.

\begin{tabular}{|c|c|c|c|c|c|c|c|c|c|}
\hline Countries & $\mathrm{EG}$ & GH-I & $\mathrm{TB}$ & GH-II & $\mathrm{TB}$ & $\beta_{1}$ & $\beta_{2}$ & $\beta_{3}$ & $\beta_{4}$ \\
\hline Denmark & -1.77 & -3.69 & 1991 & -4.24 & 1991 & $3.12(1.77)$ & $0.18(0.03)$ & $0.66(0.13)$ & \\
\hline Finland & -2.24 & -3.36 & 1989 & -4.36 & 1992 & $-12.22(1.70)$ & $24.20(2.26)$ & $1.91(0.15)$ & $-2.07(0.20)$ \\
\hline Sweden & -1.68 & -3.02 & 1988 & -4.51 & 1992 & $7.22(2.47)$ & $0.25(0.17)$ & $0.39(0.07)$ & \\
\hline Australia & -1.11 & -4.30 & 1992 & -4.45 & 1992 & $-6.49(1.62)$ & $0.28(0.05)$ & $1.31(0.08)$ & \\
\hline Canada & -2.74 & -3.85 & 1989 & -4.29 & 1993 & $-9.29(2.61)$ & $18.96(4.05)$ & $1.53(0.19)$ & $-1.38(0.30)$ \\
\hline Ireland & -1.55 & -3.54 & 1984 & -3.20 & 1984 & $3.81(1.26)$ & $0.47(0.11)$ & $0.43(0.11)$ & \\
\hline New Zealand & -1.86 & -4.20 & 1987 & -3.93 & 1988 & $-8.60(1.90)$ & $14.85(2.00)$ & $1.58(0.17)$ & $-1.29(0.18)$ \\
\hline United Kingdom & -2.51 & -4.02 & 1999 & -4.51 & 1995 & $-4.49(1.31)$ & $-0.08(0.17)$ & $1.20(0.10)$ & \\
\hline USA & -2.65 & -4.20 & 1991 & -4.32 & 1991 & $4.79(0.80)$ & $0.15(0.05)$ & $0.54(0.05)$ & \\
\hline Belgium & -2.26 & -4.84 & 1991 & -4.77 & 1992 & $1.81(0.90)$ & $0.14(0.02)$ & $0.72(0.07)$ & \\
\hline France & -2.34 & -3.34 & 1984 & -2.98 & 1994 & $-13.88(1.94)$ & $15.64(4.30)$ & $1.88(0.14)$ & $-1.11(0.31)$ \\
\hline Germany & -1.10 & -5.62 & 1992 & -5.82 & 1992 & $-5.58(1.14)$ & $0.05(0.03)$ & $1.27(0.08)$ & \\
\hline Luxembourg & -1.98 & -4.85 & 1992 & -4.84 & 1992 & $0.68(0.21)$ & $0.11(0.02)$ & $0.74(0.02)$ & \\
\hline Netherlands & -0.63 & -3.84 & 1989 & -6.39 & 1990 & $6.61(1.24)$ & $6.91(1.42)$ & $0.35(0.10)$ & $-0.54(0.11)$ \\
\hline Switzerland & -0.43 & -4.05 & 1992 & -4.09 & 1992 & $-14.98(3.15)$ & $0.34(0.25)$ & $2.01(0.25)$ & \\
\hline Greece & -2.52 & -4.56 & 1984 & -4.94 & 1992 & $-39.56(6.04)$ & $29.83(6.90)$ & $4.28(0.53)$ & $-2.59(0.60)$ \\
\hline Italy & -3.12 & -4.97 & 1991 & -5.25 & 1992 & $-8.21(1.07)$ & $6.48(2.03)$ & $1.46(0.08)$ & $-0.46(0.15)$ \\
\hline Portugal & -0.17 & -5.42 & 1992 & -5.39 & 1992 & $-10.29(0.75)$ & $0.21(0.07)$ & $1.70(0.07)$ & \\
\hline Spain & -2.42 & -3.00 & 1998 & -5.22 & 1992 & $-7.59(0.66)$ & $13.00(1.07)$ & $1.43(0.05)$ & $-0.98(0.08)$ \\
\hline Japan & 0.40 & -2.95 & 1996 & -4.24 & 1995 & $-7.47(1.40)$ & $-70.92(0.07)$ & $1.24(0.07)$ & $3.55(0.66)$ \\
\hline \multicolumn{10}{|l|}{ Group mean t-ratio } \\
\hline Raw data & 5.22 & $-2.13^{\mathrm{a}}$ & & $-5.50^{\mathrm{a}}$ & & & & & \\
\hline Cross-sec.corrected & -0.97 & $-4.07^{a}$ & & $-3.47^{a}$ & & & & & \\
\hline
\end{tabular}

This table reports the different statistics that we have employed for testing the no-cointegration null hypothesis, as well as the estimation of the most appropriate model that captures the relationship between the Non-health Social Expenditure and GDP. Column EG reports the value of the Engle-Granger statistic for each single series. Similarly, GH-I and GH-II reflect the Gregory- Hansen statistics for testing the non cointegration null hypothesis for the level shift and for the changing slope cases, respectively, TB being the estimation of the period where the break occurs. $\beta_{1}$ $\beta_{4}$ are the fully-modified estimations of the parameters of model, with their respective standard errors reported in parenthesis. Finally, the group mean t-statistics are the Pedroni and the Banerjee-Carrión statistics for testing the panel data unit root null hypothesis, with the values in italic having been obtained after removing the cross-sectional mean in order to take into account the possible correlation of the perturbations.

a means the rejection of the panel data unit root null hypothesis for a given $1 \%$ significance level. 
Annex:

Table A1: Data summary statistics of Government Social Spending as percentage of GDP. 1980-2001.

\begin{tabular}{c|ccccc}
\hline Country & Variation & Mean & Max. & Min. & S.D. \\
\hline Australia & $4.86 \%$ & $9.71 \%$ & $12.45 \%$ & $6.89 \%$ & 0.020 \\
Belgium & $2.00 \%$ & $20.77 \%$ & $22.76 \%$ & $18.59 \%$ & 0.011 \\
Canada & $1.76 \%$ & $11.92 \%$ & $14.76 \%$ & $9.39 \%$ & 0.014 \\
Denmark & $1.09 \%$ & $22.59 \%$ & $26.05 \%$ & $19.96 \%$ & 0.017 \\
Finland & $5.98 \%$ & $19.97 \%$ & $27.56 \%$ & $13.49 \%$ & 0.044 \\
France & $5.93 \%$ & $19.98 \%$ & $22.29 \%$ & $15.34 \%$ & 0.022 \\
Germany & $3.20 \%$ & $17.95 \%$ & $19.73 \%$ & $16.17 \%$ & 0.014 \\
Greece & $11.24 \%$ & $14.63 \%$ & $19.05 \%$ & $7.81 \%$ & 0.032 \\
Ireland & $-1.31 \%$ & $13.00 \%$ & $16.61 \%$ & $8.81 \%$ & 0.025 \\
Italy & $5.38 \%$ & $16.75 \%$ & $18.58 \%$ & $12.77 \%$ & 0.016 \\
Japan & $4.76 \%$ & $7.53 \%$ & $10.63 \%$ & $5.87 \%$ & 0.013 \\
Luxembourg & $-1.94 \%$ & $17.29 \%$ & $19.49 \%$ & $15.20 \%$ & 0.011 \\
Netherlands & $-5.64 \%$ & $20.80 \%$ & $24.28 \%$ & $16.09 \%$ & 0.024 \\
New Zealand & $0.24 \%$ & $13.83 \%$ & $16.23 \%$ & $11.86 \%$ & 0.013 \\
Portugal & $7.53 \%$ & $10.70 \%$ & $14.83 \%$ & $7.30 \%$ & 0.026 \\
Spain & $2.65 \%$ & $14.28 \%$ & $16.69 \%$ & $11.55 \%$ & 0.014 \\
Sweden & $1.03 \%$ & $23.47 \%$ & $29.26 \%$ & $20.43 \%$ & 0.025 \\
Switzerland & $9.28 \%$ & $14.53 \%$ & $19.73 \%$ & $9.94 \%$ & 0.039 \\
UK & $2.56 \%$ & $16.07 \%$ & $18.12 \%$ & $13.33 \%$ & 0.012 \\
USA & $-0.93 \%$ & $8.95 \%$ & $9.83 \%$ & $8.24 \%$ & 0.005 \\
\hline
\end{tabular}

Source: 2004 OECD Data Base 